\title{
STRUCTURAL AND FUNCTIONAL DEVELOPMENT IN AIRWAYS THROUGHOUT CHILDHOOD: CHILDREN ARE NOT SMALL ADULTS
}

\author{
Maria Di Cicco ${ }^{1}$, Ami Kantar ${ }^{2}$, Beatrice Masini ${ }^{1}$, Giulia Nuzzi ${ }^{1}$, Vincenzo Ragazzo ${ }^{3}$, and \\ Diego Peroni ${ }^{1}$ \\ ${ }^{1}$ University Hospital of Pisa \\ ${ }^{2}$ PEDIATRIC COUGH AND ASTHMA CENTRE \\ ${ }^{3}$ Versilia Hospital
}

August 23, 2020

\begin{abstract}
Children are not small adults, and this fact is particularly true when we consider the respiratory tract. The anatomic peculiarities of the upper airway make infants preferential nasal breather between 2 and 6 months of life. The paediatric larynx has a more complex shape than previously believed, with the narrowest point located anatomically at the subglottic level and functionally at the cricoid cartilage. Alveolarization of the distal airways starts conventionally at 36-37 weeks, but occurs mainly after birth, continuing until adolescence. The paediatric chest wall has unique features that are particularly pronounced in infants. Neonates, infants and toddlers have a higher metabolic rate, and consequently, their oxygen consumption at rest is more than double that of adults. The main anatomical and functional differences between paediatric and adult airways contribute to understanding of various respiratory symptoms and disease conditions in childhood. Knowing the peculiarities of paediatric airways is helpful in the prevention, management and treatment of acute and chronic diseases of the respiratory tract. Developmental modifications in the structure of the respiratory tract, in addition to immunological and neurological maturation, should be taken into consideration during childhood.
\end{abstract}

\section{NOSE, MOUTH AND PHARYNX}

The nose is the main entrance of the respiratory system: its external portion is particularly showy, projecting anteriorly between the orbits, but its internal portion is notably wider, starting at the nares and ending in the nasopharynx. The inner part of the nose is divided by the nasal septum into two irregularly shaped air chambers known as the nasal cavities, which communicate with the sinuses of the ethmoid, sphenoid, frontal, and maxillary bones through small orifices called ostia and are also connected with the orbits through the lachrymal canals and with the anterior cranial fossa through the olfactory foramina. In a well-conducted study, Xi et al. described the development of the nasal cavities and larynx as well as their air-flow dynamics and aerosol deposition, employing models based on computed tomography (CT) images of 4 children aged 10 days, 7 months, 3 years, and 5 years and comparing the models to a model from a 53-year-old adult (2): the study showed that the nasal cavities rapidly increase in space over the first 5 years of life, when the volume included between the nares and the larynx reaches $40.3 \%$ of that of the adult. In this study, the turbinate region, including the 3 turbinate bones located in the lateral walls of the nose, experienced the most noticeable growth during childhood and was undeveloped in both the 10-day-old and 7-month-old models. Moreover, the nostrils were described as smaller and their shape as more circular in the newborn, becoming more oval during infancy and childhood and wedge-shaped in adulthood (2), as shown in previous studies (3). Smaller nares and nasal cavities unavoidably limit the inflow of air, so it is estimated that the nose contributes up 
to $50 \%$ of total airway resistance in younger children. Unsurprisingly, even a mild nasal obstruction due to swelling or mucus production increases the work of breathing in infants and may cause respiratory distress. As far as the paranasal sinuses are concerned, the ethmoidal and maxillary sinuses are already present at birth, while the frontal and sphenoidal sinuses develop later, being radiologically demonstrated by the age of 5-6 years and adolescence, respectively (4). The main feature of the oral cavity in newborns and infants is a larger tongue, which completely occupies a much smaller oral cavity than in subsequent ages (Figure 1 - 2). Moreover, the base of the tongue is in strict connection with the epiglottis, which extends towards the velum. Infants also have a shorter neck, larger head relative to body size and a prominent occiput; as a result, when lying supine, the alignment of the oral, laryngeal and tracheal axes is hampered due to excessive neck flexion, with a high risk of upper airway obstruction and/or difficult visualization of the glottic opening during laryngoscopy. Placing a folded towel roll under the shoulders allows neutral positioning of the neck, improving airway alignment $(4,5)$. The pharynx belongs to both the respiratory and gastrointestinal tracts and is conventionally subdivided into the nasopharynx, oropharynx and hypopharynx/laryngopharynx. The paediatric pharynx is shorter and has shorter cross-sectional diameters than the adult pharynx. Moreover, the nasopharynx and oropharynx house Waldeyer's ring, which is composed of the adenoids and the lingual, tubal and palatine tonsils; these lymphatic structures are commonly enlarged in children, since they grow quickly until the age of 5-7 years and then undergo physiological atrophy (4). Studies with magnetic resonance (MR) imaging have shown that this increased mass of lymphoid tissue may contribute to airway obstruction in children (6). Last but not least, the Eustachian tubes open on the lateral wall of the nasopharynx: these structures, connecting the middle ear to the pharynx, are shorter, floppier and more horizontal at birth, facilitating mucus stagnation, and they undergo rapid growth in the first year of life $(7,8)$.

\section{LARYNX}

The larynx connects the pharynx to the trachea, and its anterior upper limit is represented, at the level of the base of the tongue, by the hyoid bone, which is a mobile, crescent-shaped bone. Notably, the hyoid bone is the first bone to ossify (4). The larynx is conventionally divided into three regions relative to the level of the vocal cords: i) the supraglottic region, which includes the epiglottis, arytenoids, aryepiglottic folds, and false vocal folds; ii) theglottic region, which includes the vocal folds and the region immediately below them; and iii) the subglottic region, which refers to the region starting $1 \mathrm{~cm}$ below the vocal folds, ending in the tracheal opening and partly corresponding to the cricoid cartilage, which is the only complete cartilage ring in the respiratory tract (4). During childhood, the larynx is located in a more cephalic and anterior position than it is during adulthood: in newborns and children up to 2 years of age, the lower limit of the cricoid cartilage lies at the level of the fourth cervical vertebra; at 6 years of age, it lies at the level of the fifth cervical vertebra, and in adulthood, it lies at the level of the sixth cervical vertebra (Figure 1 - 2) $(4,9$, 10). Due to increased acute angulation on the lower levels, visualization of the vocal cords by laryngoscopy is particularly difficult in infants and toddlers $(4,9)$. The laryngoscopic view in younger children is also hampered by the epiglottis, which appears larger, longer and omega ()-shaped. Moreover, the epiglottis lies more horizontally than it does in adults (45-degree vs 20-degree angle from the anterior pharyngeal wall). Due to the higher location of the larynx, the tip of the epiglottis almost reaches the soft palate (11): this anatomical conformation allows the infant to breathe and suckle simultaneously without aspirating due to the intermittent pression of the tongue on the soft palate (the so-called "veloglossal sphincter ") $(12,13)$ and explains why infants have long been considered "obligate nose breathers" up to age 2 - 6 months, when they improve their ability to breath by mouth apart from crying (13-15). Actually, it is not possible to infer from the literature how many infants are able to switch to oral breathing and at what age, so the term "preferential nasal breather" should be preferred, being more accurate $(16,17)$. In children, vocal cords extend posteriorly and superiorly so that they are not angled at almost 90 degrees to the trachea as they are in adults, further hampering the laryngoscopic view. Additionally, they are not linear but concave because the vocal process of the arytenoid cartilage is inclined inferiorly and medially. Unsurprisingly, articulated speech becomes possible when the larynx starts to descend (approximately around the second year of life) (12). The description of the shape and diameters of the developing larynx is one of the most debated subjects in the literature $(18,19)$ : the paediatric larynx has been considered funnel-shaped for a long time, 
with the narrowest point being at the cricoid ring until 6-8 years of age, as opposed to the adult larynx, which is cylindrical and has the narrowest point localized at the glottis opening. However, it should be emphasized that this description came from anatomical measurements of the glottic and subglottic areas in cadaveric studies, particularly from the work by Bayeux (20) and Eckenhoff (11), so the data might have been biased due to post-mortem tissue muscle tonicity loss in the portions of the larynx not supported by full circumferential cartilage. As a matter of fact, this hypothesis has recently been reconsidered in some in vivo studies: Littman and Dalal, using MR and video-bronchoscopic imaging, respectively, have shown that the paediatric larynx is conical in the transverse dimension (with the apex of the cone at the vocal cords, which is the narrowest point) and cylindrical in the anteroposterior dimension (21, 22). However, since CT is considered the gold standard for measuring the inner portions of the larynx and trachea due its spatial resolution and discrimination of the air/tissue interface $(23,24)$, this technique has been used in subsequent studies by Wani et al., which specified that the narrowest part of the paediatric larynx is located in the subglottic area (19). Specifically, these studies have clarified that the narrowest portion of the larynx in the transverse dimension is localized at the subglottic level, and in the anteroposterior dimension, it is localized at the cricoid level. However, since the subglottic area is relatively elastic and distensible, unlike the cricoid ring, which is the only circumferential complete non-distensible structure in the airways, the latter still functionally represents the narrowest portion of the paediatric larynx (23-25). More recently, Luscan et al. performed 23 measurements in the airways, from the larynx to the main bronchi, by using HRCT on 192 healthy children aged from 1 day to 14 years, providing new data suggesting that the paediatric upper airways and the main bronchi show a rapid growth phase during the first 3 years of life, followed by a slow growth phase and a second rapid growth phase during adolescence (26), similar to what has been described for height development (27). These data question the long-believed hypothesis on linear airway growth. The geometry of the cross-section of the larynx is another particularly important topic: since the studies by Littman and Dalal $(21,22)$ demonstrated that the subglottic region is more elliptical than circular in shape, as previously suggested by Bayeux, with a greater anterior-posterior dimension than transverse dimension, many physicians are shifting from the routine use of non-cuffed endotracheal tubes, previously preferred to avoid the risk of ischaemic damage to the mucosa at the cricoid level $(28,29)$, to increased use of cuffed endotracheal tubes, even in infants and younger children (30). Nonetheless, in the study by Luscan et al., the cricoid was described as having a round shape regardless of the child's age, with a diameter smaller than the anteroposterior diameter of the glottic area (26). As far as consistency, the paediatric larynx, except for the hyoid bone, is composed of non-ossified cartilaginous structures; hence, the whole structure is softer and more pliable than it is in adults, increasing the risk of airway obstruction. Complete calcification of the components of the larynx and trachea occurs in the teenage years (9).

\section{TRACHEA, BRONCHI AND BRONCHIOLES}

The trachea is shorter and narrower in children and is also angled posteriorly. Due to the higher position of the paediatric larynx, the cervical trachea segment appears to be composed of more tracheal rings in children than in adults, with 10 countable rings above the sternal notch in newborns, 8 in adolescents, and 6 or less in adults (12). Moreover, in infancy, tracheal size is approximately $50 \%, 36 \%$ and $15 \%$ of the length, diameter and cross-sectional area of an adult trachea, respectively (12). The pattern of growth of the trachea is still a matter of debate: in 1986, Griscom et al. analysed the trachea of 130 children aged $<6$ years by $\mathrm{CT}$, describing how the length, diameter and cross-sectional area grow from birth to adolescence and showed that by the end of adolescence, the length of the trachea doubles and that the mean transversal diameter is wider than the mean antero-posterior diameter in children up to the age of 6 years. These diameters increase afterwards, becoming nearly identical, so that the cross-section of the trachea becomes rounder, and at age 18 , the anteroposterior diameters usually become slightly larger $(12,31)$. Increases in tracheal length and diameter were believed to occur with a direct linear relationship from approximately 18 weeks gestation (32, 33) to age 14 in girls, while in males, tracheas continue to enlarge (but not lengthen) for a time after growth in height ceases. As previously mentioned, this pattern of growth has recently been questioned by Luscan et al., who showed a pattern of development similar to that of height and confirmed that the trachea is not round in shape, with a greater transverse diameter than anteroposterior diameter (26). 
The bronchial tree originates from the trachea, forming an asymmetric and dichotomic system of bronchi and bronchioles that are characterized by a progressive reduction of cartilage in their walls. The smaller bronchioles (diameter [?] $1 \mathrm{~mm}$ ) are not supported by cartilage in their walls and are called terminal bronchioles, representing the last generation of the airway conduction system. Their distal continuations are called respiratory bronchioles, and they show some alveoli in their walls and open in the alveolar ducts. Respiratory bronchioles, together with alveolar ducts and alveolar sacs, represent the basic functional unit of the lung, commonly known as an acinus(approximately $1 \mathrm{~cm}$ in diameter) (Figure 3) (34, 35). The "preacinar" or conducting airways are considered complete at birth, having been described as a miniature version of an adult's $(33,36)$, and only enlarge and elongate during growth, doubling or tripling their dimension up to adulthood (37). There is still some debate on the fact that the peripheral airways beyond the eighteenth generation may be disproportionately narrower than larger airways in infants and young children $(38,39)$, since a number of physiologic studies have not confirmed this pattern $(33,40-43)$.

\section{LUNG DEVELOPMENT}

While the development of conductive airways is complete at birth, the lungs undergo a prolonged period of postnatal development and maturation. Lung development is characterized by four phases (five when considering the embryonic period during which the respiratory tract rises from the foregut at approximately 3-5 weeks gestation) (Figure 4) $(35,44)$. In the first stage of lung development, the so-called "pseudoglandular phase", occurring at 5-16 weeks of gestation, the pre-acinar branching and primitive capillary plexus begin to develop, and the mesenchyme is abundant. At the end of this stage, the bronchial tree is fully developed $(45,46)$. The "canalicular phase" occurs from the 17 th to the 27 th week of gestation and is characterized by the development of acini with primitive alveoli. In this phase, type I and type II pneumocytes start to differentiate so that they can be recognized after 24 weeks of gestation (35). Moreover, an increase in capillarization, which also becomes closer to the airway surface epithelium, as well as a decrease in the amount of connective tissue, have been described, indicating the start of the development of the alveolar-capillary barrier. The "saccular phas e" starts at 28-36 weeks of gestation and continues until birth: during this phase, type II pneumocytes start to produce surfactant, saccules develop, and respiratory units differentiate. This phase is crucial: as a matter of fact, babies born before 36 weeks may show respiratory distress requiring the administration of exogenous surfactant, the severity of which is related to the degree of prematurity (46). Even if true alveoli begin to appear around the 28th week of gestation, the last phase, the "alveolar phase", starts conventionally at 37 weeks, since alveolarization occurs mainly after birth $(33,47,48)$. In fact, at birth, neonates have from 17 to 71 million alveoli, whereas adults have 200-600 million, so $85 \%$ of alveoli are added postnatally $(35,49)$. In particular, it has been reported that the volume of the lung doubles by 6 months of life, triples by 1 year (50) and increases by a factor of approximately 13 between the ages of 1 month and 7 years (35). The growth of the airways occurs more slowly than that of parenchyma, particularly in the first year of life, and this disproportionate growth pattern has been defined as "dysanaptic growth" $(48,51)$. The alveolarization process is still not completely understood (52); nevertheless, the prevailing hypothesis is that alveoli stop multiplying by 2-3 years of age and then undergo a process of increase in volume and surface area $(47,53,54)$, even if some authors have suggested that alveoli formation may continue until 7-8 years of age (55-58). A recent study by Narayanan et al. contradicts these hypotheses: in their study, alveolar dimensions were noninvasively assessed in subjects between 7 and 21 years of age by measuring self-diffusion of hyperpolarized helium-3 in the lung periphery during a brief breath-hold using MR (59). The results of the study show that alveolar size does not increase, and thus, the described 3- to 4-fold increase in lung volume between 7 years and adulthood (60) could only be explained by neo-alveolarization through childhood and adolescence. This finding could be noteworthy considering the chances of recovery for children having suffered early lung damage due to respiratory diseases as well as several detrimental environmental factors $(51,52)$. Regarding differences between sexes, it should be noted that boys have more alveoli but the same mean alveolar size as females; therefore, they have larger lungs at any given age. Males also have more respiratory bronchioles than females, since the number of alveoli supplied from one respiratory bronchiole is the same in boys and girls (61). These differences may be caused by the influence of sex hormones on lung development, especially in adolescence, when remarkable changes also occur to the thoracic cage in terms 
of anatomy and muscle power $(35,46)$. Last but not least, it should be noted that even if children have fewer alveoli, their air-blood contact surface ratio is $1 \mathrm{~m}^{2} / \mathrm{kg}$, which is almost the same as that in adults. Nonetheless, infants lack interalveolar pores of Kohn (62), bronchiolar-alveolar channels of Lambert (63) and interbronchiolar channels of Martin (64), which are compensatory structures linking alveoli with each other, alveoli to bronchioles, or bronchioles to each other, respectively, to facilitate collateral ventilation overcoming distal obstructions (Figure 3) $(65,66)$. The development of these structures is usually complete by the 12 th month of life $(52,67-69)$.

\section{CHEST WALL AND RESPIRATORY MUSCLES}

The paediatric chest wall has unique features and undergoes significant developmental changes during growth in terms of shape, compliance, and deformability (48). In newborns and infants, the ribs have a typical horizontal orientation, and the transverse chest section is almost circular, rather than oval: when they adopt an upright posture, gravitational forces gradually change the orientation of the ribs and chest section, as clearly noticeable in chest X-rays and CT scans (Figure 5) $(70,71)$. The horizontal orientation of the ribs makes it challenging for younger children to elevate them as adults do with the normal "bucket handle" effect to enlarge the rib cage and the thoracic volume: this unique feature contributes to the fixity of tidal volume (TV) during childhood so that ventilation is primarily diaphragmatic and respiratory dynamics are less efficient $(72,73)$. Moreover, in children, costae consist mainly of cartilage, which makes the rib cage highly compliant, further reducing respiratory pump efficiency $(70,71)$. The diaphragm also has a more horizontal position, being flatter than in adults; therefore, its ability to contract is limited. External and internal intercostal muscles are not well developed in children, especially in infants. As a result, contraction of these muscles cannot contribute to enlargement of the chest wall as in adults, and their contribution to respiratory effort and tidal volume is minimal (73). Instead, these muscles act primarily to stabilize the more compliant chest wall, minimizing the inward displacement of the rib cage caused by negative intrathoracic pressure produced by downward diaphragmatic contraction (70). Moreover, in infancy, respiratory muscles are mainly composed of type II fibres (fatigue-susceptible, due to lower stores of glycogen and fat) since type I fibres (fatigue-resistant) develop later in life $(73,74)$. Consequently, children have greater susceptibility to ventilator muscle fatigue when the respiratory rate $(\mathrm{RR})$ is increased, and this is particularly true in preterm infants who have the lowest percentage of type I fibres $(74,75)$. At the age of 2 years, the diaphragm is composed of $55 \%$ type I fibres (74). Smooth muscle begins to appear in the airways at 6-8 weeks of gestation, and its amount continues to grow during childhood, with a progressive increase in beta-adrenoreceptors, particularly noticeable in the first year of life $(34,76)$.

\section{RESPIRATORY SYSTEM PHYSIOLOGY IN CHILDHOOD}

In addition to the anatomical differences that we have described so far (Table 1), the respiratory system is also characterized by physiological peculiarities in childhood. First, since birth and up to school age, children have a higher metabolic rate, with a rate of oxygen consumption at rest that is more than double that of adults $(7-9 \mathrm{~mL} / \mathrm{kg} / \mathrm{min}$ vs $3 \mathrm{~mL} / \mathrm{kg} / \mathrm{min}$ ) (1). Moreover, in the case of hypoxia, oxygen release decreases even more due to bradycardia caused by activation of the parasympathetic nervous system, whose activity is dominant in newborns and infants. Because children have a mostly stable TV, the only way to guarantee the required oxygen supply at rest is through a higher respiratory rate (RR) (77): normal paediatric RR values during rest were described in evidence-based percentile charts by Fleming et al. in 2011, demonstrating how RR declines from birth to adolescence, with the steepest fall at 2 years of age (78). Considering that TV cannot be increased considerably and that minute ventilation (MV) is equal to RR multiplied by TV, when experiencing respiratory distress, infants must increase their RR to increase MV (79). However, when RR increases too much, TV starts to decrease (28). Notably, TV in infants is approximately $15 \mathrm{~mL}$, while it is approximately $500 \mathrm{~mL}$ in adults (33), and MV is estimated to be $500 \mathrm{~mL} / \mathrm{min}$ in infants and approximately $6 \mathrm{~L} / \mathrm{min}$ in adults. All lung volumes are obviously reduced in children, and the difference is particularly noticeable in functional residual capacity (FRC), which is approximately $80 \mathrm{~mL}$ in newborns and $3,000 \mathrm{~mL}$ in adults $(35,49)$. FRC is defined as the static passive balance between the inward collapse of the lungs and the outward pull of the chest wall: in children, this balance is achieved at a very small FRC because 
the outward pull of the chest is small due to the compliance of the rib cage (35). FRC can be functionally considered a respiratory reserve (70): in infants, a reduced FRC results in less air available in the lungs for gas exchange, especially during respiratory distress or when lying supine (i.e., when the lungs are compressed by ascended abdominal contents). In newborns and infants, FRC decreases during deep sleep and sedate states more than in adults because the chest wall is more compliant and muscle tone decreases more easily, so that during the period of apnoea, they undergo desaturation more rapidly. (28). However, in the first 6-12 months of life, infants can dynamically increase their FRC by actively modulating their expiration flow via post-inspiratory activity of the diaphragm $(48,80)$ and laryngeal narrowing during expiration (81). Finally, it is important to remember that airway resistance is described by Poiselle's Law: $\mathrm{R}=8 \eta \mathrm{L} / \pi \mathrm{r}^{4}$ : as shown in this equation, resistance $(\mathrm{R})$ to flow is inversely proportional to the radius $(\mathrm{r})$ of the airway raised to the fourth power (in the equation, $\eta$ is the coefficient of viscosity of the air, $L$ is the length of the airway, and $\mathrm{V}$ is the airflow volume). This means that a small narrowing (for example, due to oedema) results in significant obstruction in children with a large impact on airway resistance (Figure 6). Moreover, although the airway diameter decreases from the trachea to the terminal airways, there is a gradual increase in the cross-sectional area due to the increase in the number of airways, so peripheral resistance is notably less significant (47). Last but not least, even the cough reflex undergoes a process of maturation in the very first months of life; unsurprisingly, some studies have shown that newborns and infants respond to external stimuli in the pharynx, such as the introduction of water or saline, mainly with swallowing, apnoea and laryngeal closure (82).

CONCLUSIONS The paediatric airways are far from being just a smaller version of adult airways since they have many anatomical and physiological peculiarities that explain many symptoms and disease conditions in childhood. Some of these factors may contribute to the rapid development of respiratory distress in childhood (Table 2). These factors should be well known and kept in mind when managing acute and/or chronic airway disease and/or respiratory distress in infants and preschool-age children. Knowing the peculiarities of paediatric airways is helpful in the prevention, management and treatment of acute and chronic diseases of the respiratory tract.

\section{ACKNOWLEDGEMENTS: None}

CONFLICTS OF INTEREST: The authors have no conflicts of interest to declare.

\section{REFERENCES}

1. Belanger J, Kossick M. Methods of identifying and managing the difficult airway in the pediatric population. AANA J . 2015; 83: 35-41.

2. Xi J, Si X, Zhou Y, Kim J, Berlinski A. Growth of nasal and laryngeal airways in children: implications in breathing and inhaled aerosol dynamics. Respir Care . 2014; 59: 263-73.

3. Pedersen OF, Berkowitz R, Yamagiwa M, Hilberg O. Nasal cavity dimensions in the newborn measured by acoustic reflections. Laryngoscope . 1994; 104: 1023-8.

4. Adewale L. Anatomy and assessment of the pediatric airway. Paediatr Anaesth . 2009; 19: 1-8.

5. Vialet R, Nau A, Chaumoître K, Martin C. Effects of head posture on the oral, pharyngeal and laryngeal axis alignment in infants and young children by magnetic resonance imaging. Paediatr Anaesth . 2008; 18: $525-31$.

6. Arens R, McDonough JM, Costarino AT, Mahboubi S, Tayag-Kier CE, Maislin G, Schwab RJ, Pack AI. Magnetic resonance imaging of the upper airway structure of children with obstructive sleep apnea syndrome. Am J Respir Crit Care Med . 2001; 164: 698-703.

7. Ishijima K, Sando I, Balaban C, Suzuki C, Takasaki K. Length of the eustachian tube and its postnatal development: computer-aided three-dimensional reconstruction and measurement study. Ann Otol Rhinol Laryngol . 2000; 109: 542-8.

8. Bluestone CD. Humans are born too soon: impact on pediatric otolaryngology. Int J Pediatr Otorhinolaryngol . 2005; 69: 1-8.

9. Hudgins PA, Siegel J, Jacobs I, Abramowsky CR. The normal pediatric larynx on CT and MR. AJNR Am J Neuroradiol . 1997; 18: 239-45. 
10. Dickison AE. The normal and abnormal pediatric upper airway. Recognition and management of obstruction. Clin Chest Med . 1987; 8: 583-96.

11. Eckenhoff JE. Some anatomic considerations of the infant larynx influencing endotracheal anesthesia. Anesthesiology . 1951; 12: 401-10.

12. Monnier P. Applied Surgical Anatomy of the Larynx and Trachea. In P. Monnier (ed.), Pediatric Airway Surgery, Springer-Verlag Berlin Heidelberg 2011; pp 7-29.

13. Moss ML. The veloepiglottic sphincter and obligate nose breathing in the neonate. J Pediatr. 1965; 67: 330-5.

14. Miller MJ, Carlo WA, Strohl KP, Fanaroff AA, Martin RJ. Effect of maturation on oral breathing in sleeping premature infants. J Pediatr . 1986; 109: 515-9.

15. Polgar G, Kong GP. The nasal resistance of newborn infants. J Pediatr . 1965; 67: 557-67.

16. Rodenstein DO, Perlmutter N, Stănescu DC. Infants are not obligatory nasal breathers. Am Rev Respir Dis . 1985; 131: 343-7.

17. Bergeson PS, Shaw JC. Are infants really obligatory nasal breathers? Clin Pediatr (Phila) . 2001; 40: 567-9.

18. Holzki J, Brown KA, Carroll RG, Coté CJ. The anatomy of the pediatric airway: Has our knowledge changed in 120 years? A review of historic and recent investigations of the anatomy of the pediatric larynx. Paediatr Anaesth . 2018; 28: 13-22.

19. Wani TM, Bissonnette B, Engelhardt T, Buchh B, Arnous H, AlGhamdi F, Tobias JD. The pediatric airway: Historical concepts, new findings, and what matters. Int J Pediatr Otorhinolaryngol . 2019; 121: 29-33.

20. Bayeux. Tubage de larynx dans le Croup. Presse Med. 1897; $20: 1$.

21. Litman RS, Weissend EE, Shibata D, Westesson PL. Developmental changes of laryngeal dimensions in unparalyzed, sedated children. Anesthesiology . 2003; 98: 41-5.

22. Dalal PG, Murray D, Messner AH, Feng A, McAllister J, Molter D. Pediatric laryngeal dimensions: an age-based analysis. Anesth Analg . 2009; 108: 1475-9.

23. Wani TM, Rafiq M, Akhter N, AlGhamdi FS, Tobias JD. Upper airway in infants-a computed tomography-based analysis. Paediatr Anaesth . 2017; 27: 501-5.

24. Wani TM, Rafiq M, Talpur S, Soualmi L, Tobias JD. Pediatric upper airway dimensions using threedimensional computed tomography imaging. Paediatr Anaesth . 2017; 27: 604-8.

25. Wani TM, Bissonnette B, Rafiq Malik M, Hayes D Jr, Ramesh AS, Al Sohaibani M, Tobias JD. Agebased analysis of pediatric upper airway dimensions using computed tomography imaging. Pediatr Pulmonol . 2016; 51: 267-71.

26. Luscan R, Leboulanger N, Fayoux P, Kerner G, Belhous K, Couloigner V, Garabedian EN, Simon F, Denoyelle F, Thierry B. Developmental changes of upper airway dimensions in children. Paediatr Anaesth . 2020; 30: 435-45.

27. Karlberg J. A biologically-oriented mathematical model (ICP) for human growth. Acta Paediatr Scand Suppl . 1989; 350: 70-94.

28. Santillanes G, Gausche-Hill M. Pediatric airway management. Emerg Med Clin North Am . 2008; 26: 961-75.

29. Sims C, von Ungern-Sternberg BS. The normal and the challenging pediatric airway. Paediatr Anaesth . 2012; 22: 521-6.

30. Tobias JD. Pediatric airway anatomy may not be what we thought: implications for clinical practice and the use of cuffed endotracheal tubes. Paediatr Anaesth . 2015; 25: 9-19.

31. Griscom NT, Wohl ME. Dimensions of the growing trachea related to age and gender. AJR Am $J$ Roentgenol . 1986; 146: 233-7.

32. Szpinda M, Daroszewski M, Woźniak A, Szpinda A, Mila-Kierzenkowska C. Tracheal dimensions in human fetuses: an anatomical, digital and statistical study. Surg Radiol Anat . 2012; 34: 317-23.

33. Hislop A, Muir DC, Jacobsen M, Simon G, Reid L. Postnatal growth and function of the pre-acinar airways. Thorax . 1972; 27: 265-74.

34. Jeffrey PK. The development of large and small airways. Am J Respir Crit Care Med . 1998; 157: 
S174-80

35. Merkus PJ, ten Have-Opbroek AA, Quanjer PH. Human lung growth: a review. Pediatr Pulmonol . 1996; 21: 383-97.

36. Bucher U, Reid L. Development of the intrasegmental bronchial tree: the pattern of branching and development of cartilage at various stages of intra-uterine life. Thorax . 1961; 16: 207-18.

37. Hislop AA, Haworth SG. Airway size and structure in the normal fetal and infant lung and the effect of premature delivery and artificial ventilation. Am Rev Respir Dis . 1989; 140: 1717-26.

38. Bryan AC, Wohl MEB. Respiratory mechanics in children. In: Fishman AP, Macklem PT, Mead J (eds) Mechanics of breathing, part 2. (Handbook of physiology, section 3. The respiratory system, vol III) 1986 American Physiological Society, Bethesda, Md.; pp 179-91.

39. Hogg JC, Williams J, Richardson JB, Macklem PT, Thurlbeck WM. Age as a factor in the distribution of lower-airway conductance and in the pathologic anatomy of obstructive lung disease. $N$ Engl $\mathrm{J} \mathrm{Med}$ . 1970; 282: 1283-7.

40. Motoyama EK. Pulmonary mechanics during early postnatal years. Pediatr Res . 1977; 11: 220-3.

41. Taussig LM, Landau LI, Godfrey S, Arad I. Determinants of forced expiratory flows in newborn infants. J Appl Physiol Respir Environ Exerc Physiol . 1982; 53: 1220-7.

42. Hoch H, Mallory GB Jr, Taussig L. Retrospectoscope: Are the peripheral airways in infants and young children disproportionately small, putting them at risk for severe respiratory illnesses?. Pediatr Pulmonol . 2017; 52: 1405-7.

43. Horsfield K, Gordon WI, Kemp W, Phillips S. Growth of the bronchial tree in man. Thorax . 1987; 42: $383-8$.

44. Ornitz DM, Yin Y. Signaling networks regulating development of the lower respiratory tract. Cold Spring Harb Perspect Biol . 2012; 4: a008318. Published 2012 May 1.

45. Reid LM. Lung growth in health and disease. Br J Dis Chest . 1984; 78: 113-34.

46. Rosenthal M, Bush A. The growing lung: normal development, and the long-term effects of pre- and postnatal insults. Eur Respir Mon 2002; 19: 1-24.

47. Hislop AA. Airway and blood vessel interaction during lung development. J Anat . 2002; 201: 325-34.

48. Dezateux C, Stocks J. Lung development and early origins of childhood respiratory illness. $\mathrm{Br} \mathrm{Med}$ Bull . 1997; 53: 40-57.

49. Dunnill MS. The problem of lung growth. Thorax . 1982; 37: 561-3.

50. Green M, Mead J, Turner JM. Variability of maximum expiratory flow-volume curves. J Appl Physiol . 1974; 37: 67-74.

51. Merkus PJ. Effects of childhood respiratory diseases on the anatomical and functional development of the respiratory system. Paediatr Respir Rev . 2003; 4: 28-39.

52. Burri PH. Structural aspects of postnatal lung development - alveolar formation and growth. Biol Neonate . 2006; 89: 313-22.

53. Zeltner TB, Burri PH. The postnatal development and growth of the human lung. II. Morphology. Respir Physiol . 1987; 67: 269-82.

54. Thurlbeck WM. Postnatal human lung growth. Thorax . 1982; 37: 564-71.

55. Dunnill MS. Postnatal Growth of the Lung. Thorax . 1962; 17: 329-33.

56. Weibel ER, Gomez DM. A principle for counting tissue structures on random sections. J Appl Physiol . 1962; 17: 343-8.

57. de Jong PA, Nakano Y, Lequin MH, et al. Estimation of lung growth using computed tomography. Eur Respir J . 2003; 22: 235-8.

58. Davies G, Reid L. Growth of the alveoli and pulmonary arteries in childhood. Thorax . 1970; 25: $669-81$.

59. Narayanan M, Owers-Bradley J, Beardsmore CS, Mada M, Ball I, Garipov R, Panesar KS, Kuehni CE, Spycher BD, Williams SE et al. Alveolarization continues during childhood and adolescence: new evidence from helium-3 magnetic resonance. Am J Respir Crit Care Med . 2012; 185: 186-91.

60. Rosenthal M, Cramer D, Bain SH, Denison D, Bush A, Warner JO. Lung function in white children aged 4 to 19 years: II-Single breath analysis and plethysmography. Thorax . 1993; 48: 803-8. 
61. Calogero C, Sly PD. Developmental physiology: lung function during growth and development from birth to old age. Eur Respir Monograph. 2010: 1-15.

62. Kohn HN. Zur histologie der indurirenden fibrinosen pneumonie [in German] Munch Med Wochenschr . 1893; 40: 42-4.

63. Lambert MW. Accessory bronchiolealveolar communications. J Pathol Bacteriol . 1955; 70: 311-4.

64. Martin HB. Respiratory bronchioles as the pathway for collateral ventilation. J Appl Physiol . 1966; 21: $1443-7$.

65. Terry PB, Traystman RJ. The Clinical Significance of Collateral Ventilation. Ann Am Thorac Soc . 2016; 13: 2251-7.

66. Raskin SP, Herman PG. Interacinar pathways in the human lung. Am Rev Respir Dis . 1975; 111: 489-95.

67. Walsh BK, Hood K, Merritt G. Pediatric airway maintenance and clearance in the acute care setting: how to stay out of trouble. Respir Care . 2011; 56: 1424-44.

68. Boyden EA. Notes on the development of the lung in infancy and early childhood. Am J Anat . 1967; 121: 749-61.

69. Weiss MJ, Burri PH. Formation of interalveolar pores in the rat lung. Anat Rec . 1996; 244: 481-9.

70. Gaultier C. Respiratory muscle function in infants. Eur Respir J . 1995; 8: 150-3.

71. Papastamelos C, Panitch HB, England SE, Allen JL. Developmental changes in chest wall compliance in infancy and early childhood. J Appl Physiol (1985) . 1995; 78: 179-84.

72. Openshaw P, Edwards S, Helms P. Changes in rib cage geometry during childhood. Thorax . 1984; 39: 624-7.

73. Greenspan JS, Miller TL, Shaffer TH. The neonatal respiratory pump: a developmental challenge with physiologic limitations. Neonatal Netw . 2005; 24: 15-22.

74. Keens TG, Bryan AC, Levison H, Ianuzzo CD. Developmental pattern of muscle fiber types in human ventilatory muscles. J Appl Physiol Respir Environ Exerc Physiol . 1978; 44: 909-13.

75. Keens TG, Ianuzzo CD. Development of fatigue-resistant muscle fibers in human ventilatory muscles. Am Rev Respir Dis . 1979; 119: 139-41.

76. Tepper RS. Airway reactivity in infants: a positive response to methacholine and metaproterenol. $J$ Appl Physiol (1985) . 1987; 62: 1155-9.

77. Rusconi F, Castagneto M, Gagliardi L, Leo G, Pellegatta A, Porta N, Razon S, Braga M. Reference values for respiratory rate in the first 3 years of life. Pediatrics . 1994; 94: 350-5.

78. Fleming S, Thompson M, Stevens R, Heneghan C, Plüddemann A, Maconochie I, Tarassenko L, Mant D. Normal ranges of heart rate and respiratory rate in children from birth to 18 years of age: a systematic review of observational studies. Lancet . 2011; 377: 1011-8.

79. Mortola JP. Breathing pattern in newborns. J Appl Physiol Respir Environ Exerc Physiol . 1984; 56: 1533-40.

80. Kosch PC, Hutchinson AA, Wozniak JA, Carlo WA, Stark AR. Posterior cricoarytenoid and diaphragm activities during tidal breathing in neonates. J Appl Physiol (1985) . 1988; 64: 1968-78.

81. Harding R, Johnson P, McClelland ME. Respiratory function of the larynx in developing sheep and the influence of sleep state. Respir Physiol . 1980; 40: 165-79.

82. Thach BT. Maturation of cough and other reflexes that protect the fetal and neonatal airway. Pulm Pharmacol Ther . 2007; 20: 365-70.

\section{Hosted file}

Table 1 - Main differences between the pediatric and adult airways.docx available at https://authorea.com/users/352150/articles/476505-structural-and-functional-developmentin-airways-throughout-childhood-children-are-not-small-adults

\section{Hosted file}

Table 2 - Main factors predisposing infants to rapid oxygen desaturation and respiratory failure.docx available at https://authorea.com/users/352150/articles/476505-structural-and-functional- 
development-in-airways-throughout-childhood-children-are-not-small-adults
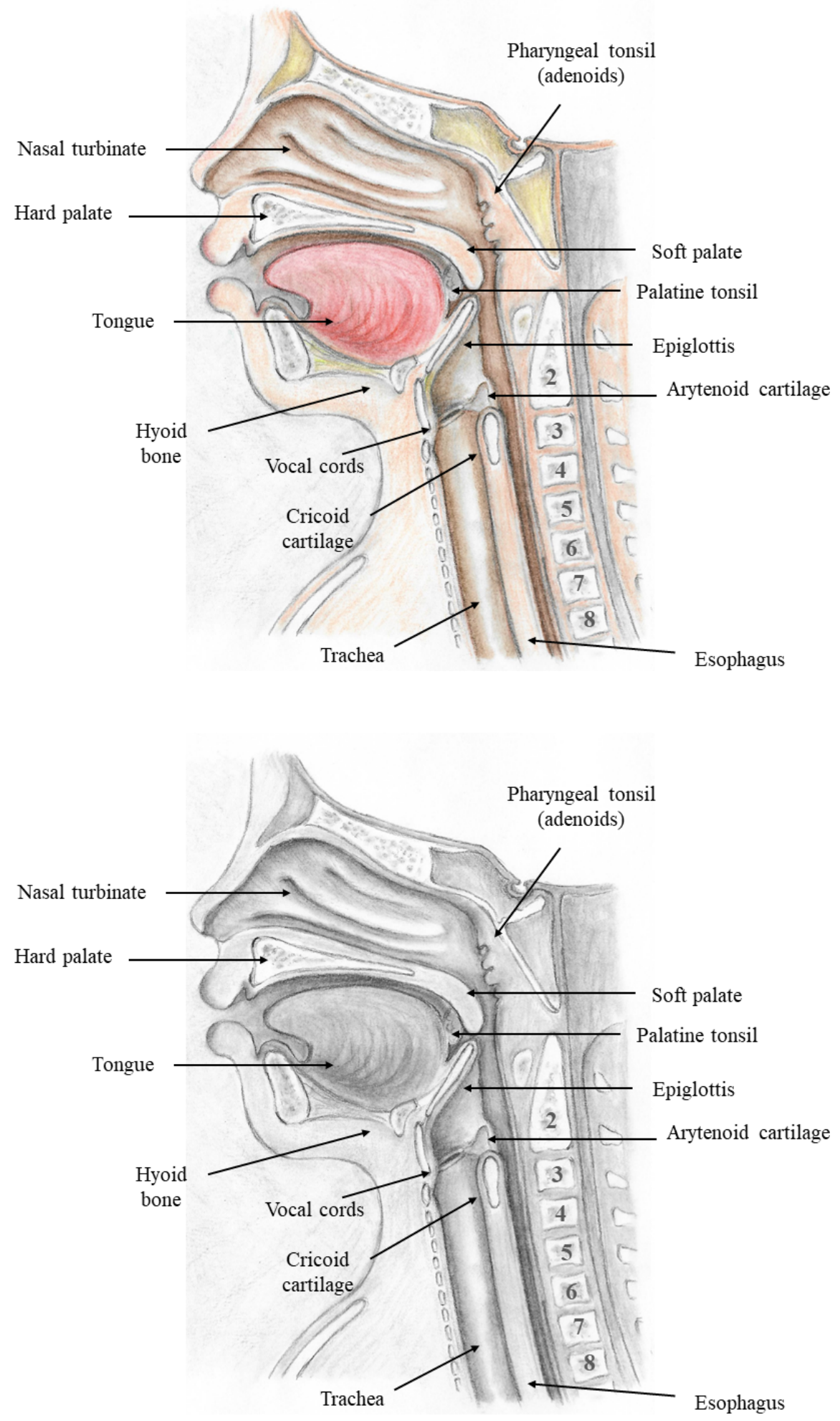

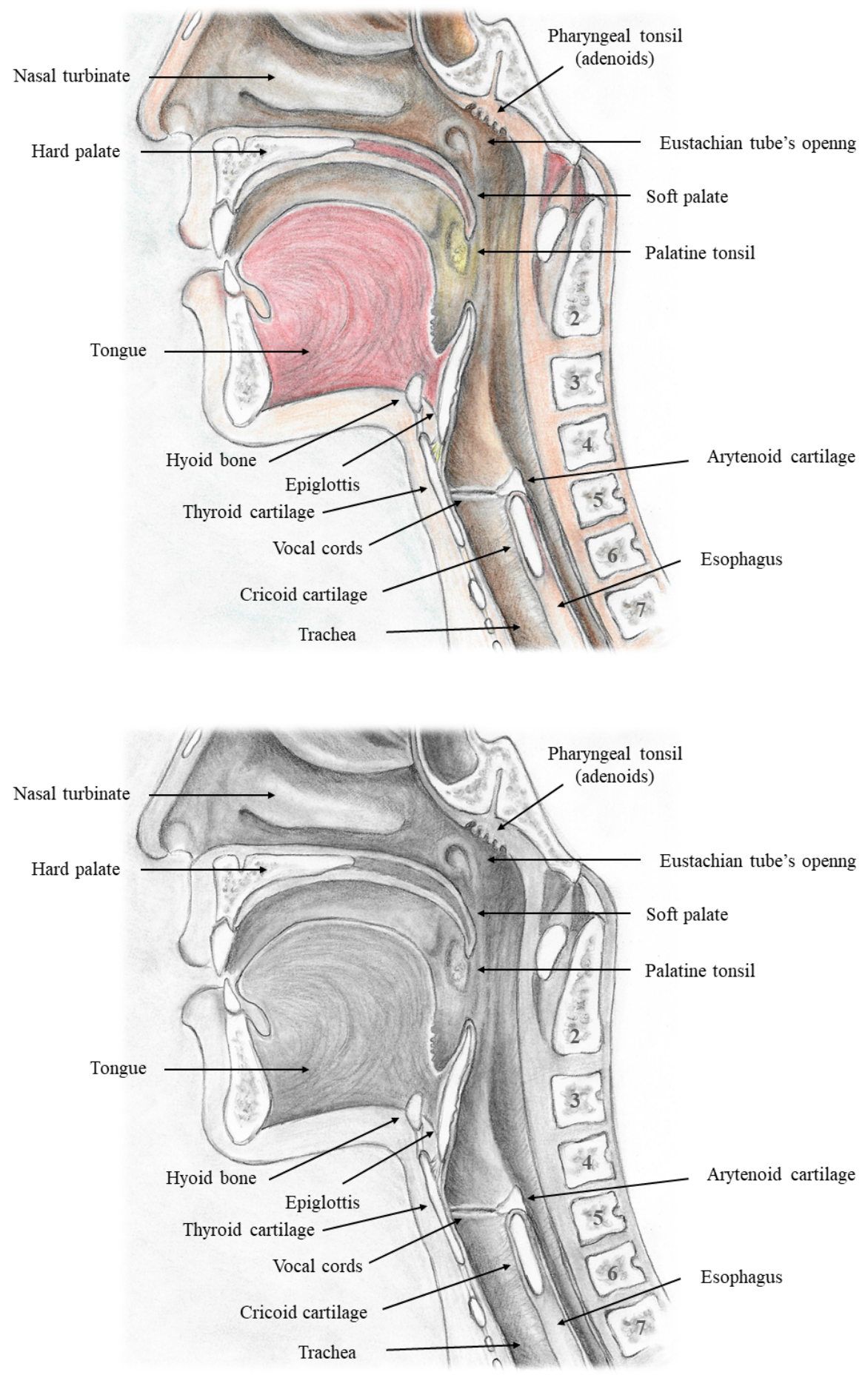

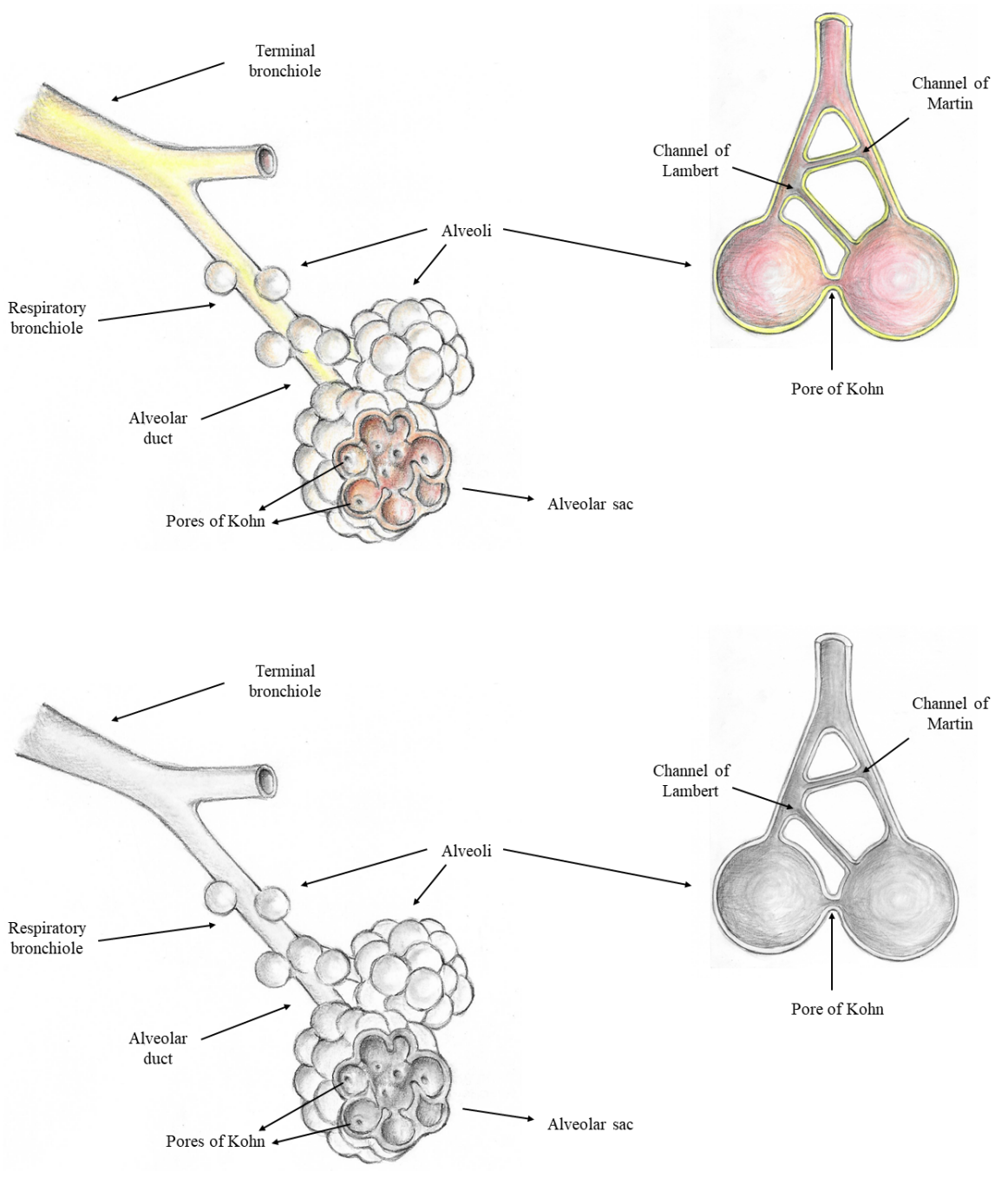

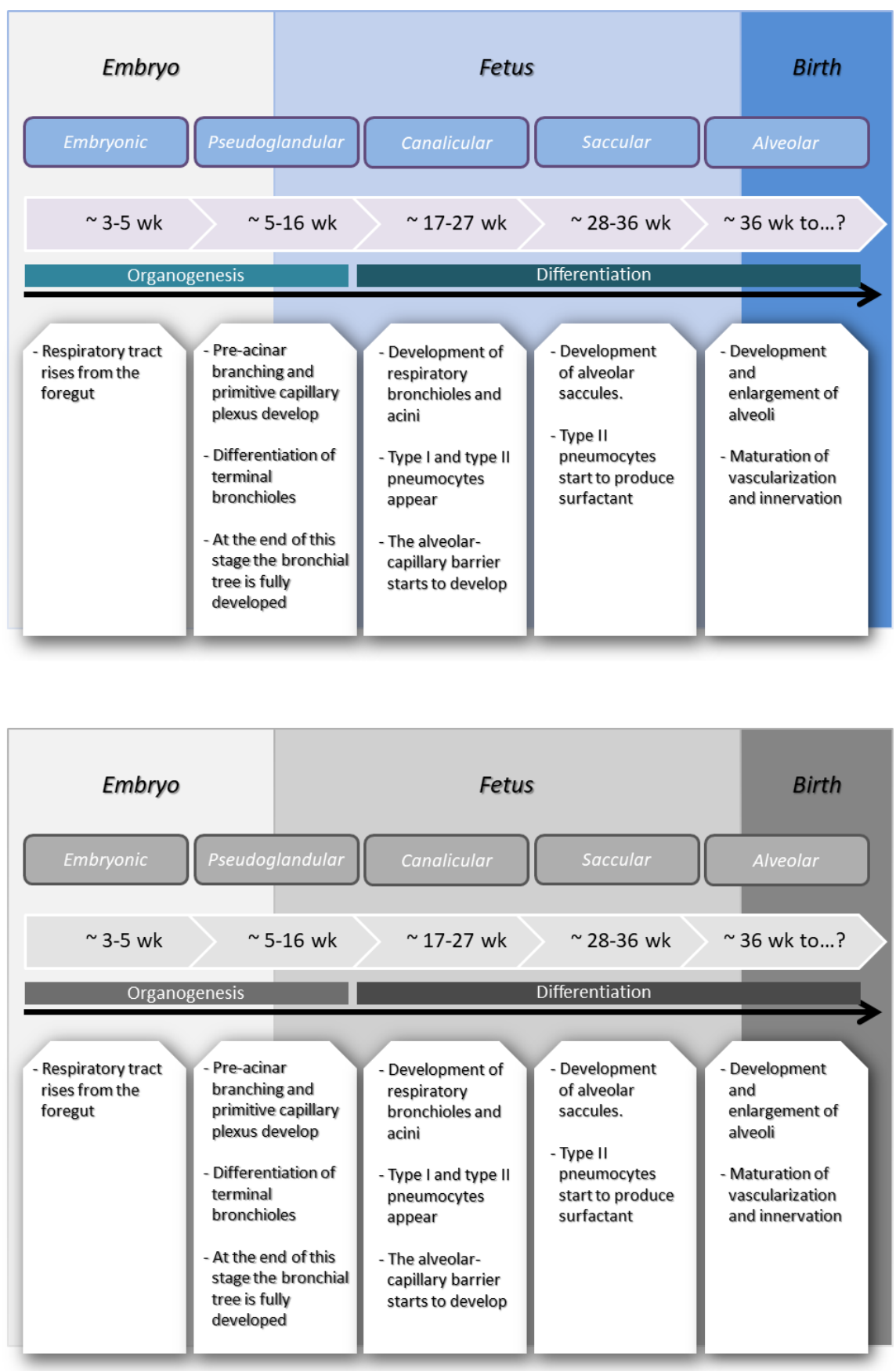


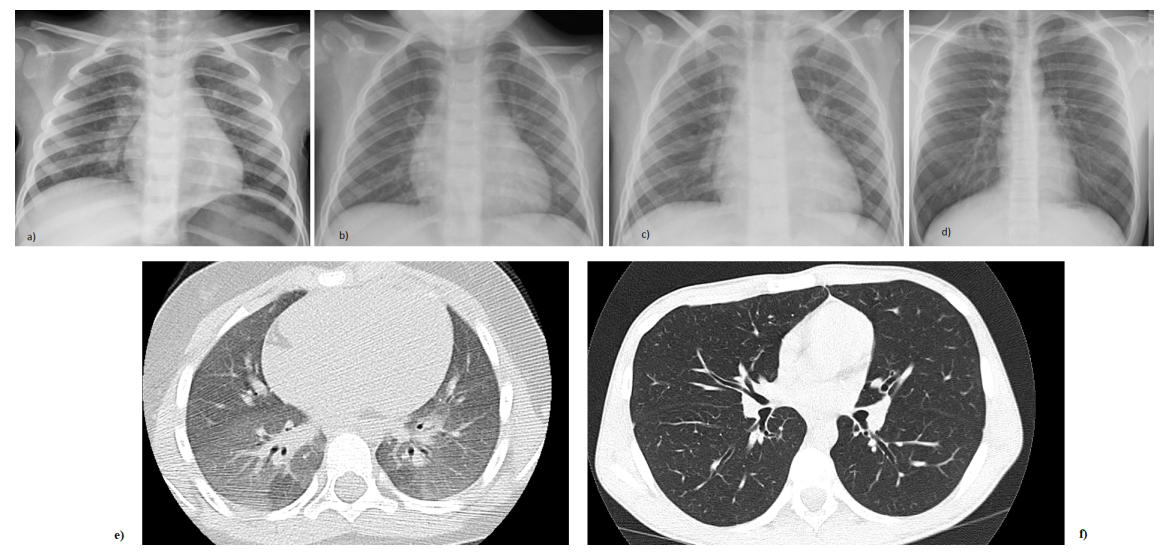

Poiseuille's Law: $R=8 \eta \mathrm{l} / \pi \mathrm{r}^{4}$

Healthy airways Oedema $(1 \mathrm{~mm}) \quad$ Decrease of the cross-sectional area

Child $\longrightarrow$

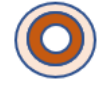

$\downarrow 75 \%$

Adult
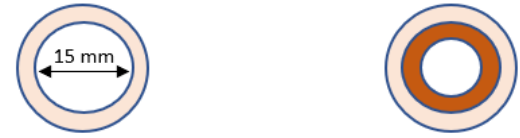

$25 \%$

\section{Poiseuille's Law: $\quad R=8 \eta \mathrm{l} / \pi \mathrm{r}^{4}$}

Healthy airways

Oedema (1 mm)

Decrease of the cross-sectional area

Child

$\stackrel{4}{\hookrightarrow}$

(0)

$\downarrow 75 \%$

Adult $\longrightarrow$

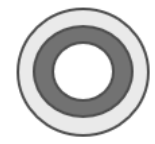

$25 \%$ 